\title{
WY Dependence - A Case Report from Manipur
}

\author{
Khangembam Robindro Singh ${ }^{1}$, Mhetre Bhushan B ${ }^{2}$, R.K. Lenin Singh ${ }^{3}$ \\ ${ }^{1,3,}$ Department of Psychiatry, RIMS, Imphal, Manipur, \\ ${ }^{2}$ Department of Psychiatry, SKN Medical College, Pune, Maharashtra
}

\begin{abstract}
WY commonly known among users as "World is yours" are methamphetamine tablets. These contain methamphetamine $25-35 \mathrm{mg}$, very addictive stimulant drug along with caffeine 45-65mg. At comparable doses, the effects of methamphetamine are much more potent, longer lasting and more harmful than amphetamine to the cardiovascular and central nervous system. WY can be ingested, snorted, smoked, or injected. Myanmar is the highest illegal production center of WY by smuggling maximum amount of easily available precursors, ephedrine and pseudoephedrine from India. Manipur, being at the international border (through Moreh Town) to Myanmar is now becoming the targeted smuggling centre for WY and it becomes now an area of great concern.
\end{abstract}

KEY WORD: - Methamphetamine, Ephedrine, Pseudoephedrine, Precursors, Addiction, Manipur.

\section{INTRODUCTION}

Methamphetamine dependence is a serious worldwide public health problem with major medical, psychiatric, socio economic \& legal consequences. Incidence of addiction to certain drugs amongst young people in our country has been increasing ${ }^{1}$ Drug abuse directly influences the economic and social aspects of a country other than the personal and family life of the individual. There are thousands of drug dependent people in India (particularly in Manipur) and most of them are young, between the ages of 16 and 45. Manipur is a border state to Myanmar which forms a part of the 'golden triangle' (Myanmar, Thailand and Laos) in terms of geographical location.. Being a border state, Manipur is becoming a major transit point for drug trafficking. Crystal methamphetamine is the hydrochloride salt of methamphetamine. Heating and inhaling crystalline methamphetamine fumes (or 'chasing the white dragon') is the most rapid method of obtaining a 'high'. Methamphetamine hydrochloride is dissolvable in water and can be injected or ingested as a liquid. Methamphetamine powder is readily absorbed across mucus membranes and can be snorted, ingested or inserted rectally. Powder can be injected, as a 'dry shot' ${ }^{2}$. WY (Methamphetamine) is a powerful central nervous system stimulant with longer lasting effects than those of cocaine. This is because cocaine metabolized in the body more quickly than methamphetamine. Acute effects of WY include: increased attention, decreased fatigue, increased activity, decreased appetite, euphoria and rush, increased respiration, hyperthermia. Effects of chronic abuse include: dependence, addiction psychosis, paranoia, hallucinations, mood disturbances, repetitive motor activity, weight loss, stroke ( damage to the small blood vessels in the brain), myocardial infarction (increased heart rate, blood pressure $)^{3}$.

\section{CASE HISTORY}

A 40 year old Manipuri Muslim from urban middle class family working as rifleman in IRB reported to the Department of Psychiatry, RIMS, Manipur on 25/01/2013 with the history of chasing WY for about 4 years and withdrawal symptoms for 25 days after abstinence. He started chasing WY during later part of 2009 when one of his friends who was already addicted to this drug introduced him WY as the means of enjoyment. Initially he started chasing only one tablet of WY. He further increased the dose to 2 to 3 tablets per day, particularly at night for a few days. After chasing he experienced alertness with increased energy, euphoria, talkativeness and insomnia. He developed overconfidence that he could continue his night patrol for 3 consecutive nights without taking any rest or sleep. The "high" lasted for about 12-14 hours. After about $14 \mathrm{hrs,}$ he became restless, anxious with loss of appetite. He developed an urge to chase the drug. He had difficulty in concentration, thinking and decision making process. It took about 24 hours for him to feel sleepy. He could not stay at his battalion/regiment and became very restless because of the urge and this compelled him to chase WY with subsequent increase in the dose from $2-3$ tablets to 5 tablets per day. However, the frequency and the number of doses were varied depending on his financial situation. He used to take a minimum of 5 tablets per day despite his financial problem. Most of his salary was spent for the drug and he became financially constrained. His health was also deteriorating. He often lied to friends, families and parents to get money. He 
felt guilty and decided to stop the habit but could not. Intense craving, severe body ache, and insomnia distressed him. He could not spend a single night without the drug. To get rid of the unwanted effects he continued taking the drug again and again. By this time, he said, taking the drug was not to get "high" but to overcome the feelings of discomfort. He attempted to stop taking the drug many times during the period of 4 years but was unsuccessful. After becoming a chronic user he experienced weight reduction (from $68 \mathrm{~kg}$ to 60 $\mathrm{kg}$ ). He became lean and thin, malnourished with change of complexion (darken); experienced pounding heart beat, weakness, dizziness, decreased sex drive and also anxious feeling of dying. He also had repeated episodes of crying. With a strong determination to discontinue WY, he stopped chasing it from first January 2013. He presented symptoms of inability to fall asleep, body ache, decreased appetite, inability to concentrate, anxious feeling, and generalized weakness along with fear of dying for about 22 days following withdrawal of the drug. These were complicated by repeated vomiting with persistent generalized weakness for another 2 days. He was admitted in the psychiatry ward. He denied history of abuse of other drugs. Pre-morbid personality was well adjusted, sober, and faithful.

$\mathrm{He}$ is thinly built and poorly nourished as revealed by physical examination. $\mathrm{BP}=140 / 86 \mathrm{mmHg}$; $\mathrm{RR}=16 / \mathrm{min}$ and weight $=60 \mathrm{~kg}$ (before drug use weight was $68 \mathrm{~kg}$ ). Systemic examination and neurological examination were within normal limits. Mental Status Examination (MSE) on admission revealed low mood with dysphoric and apprehensive affect. Routine investigation reports were normal except KFT (urea= 57) and LFT (SGPT $=140$ ) which were mildly deranged. HBsAg, HCV \& Retro antibody were negative. ECG showed sinus tachycardia but Chest X-ray P/A was normal. Score on Hamilton anxiety rating scale and Beck depression scale showed mild anxiety (Score 17) and moderate depression (Score 22).

He was managed with symptomatic treatment including intravenous fluids, Inj. Pantoprazole and Inj. Ondansetrone. Inj. Lorazepam was given intramuscularly for sleep for initial 3 days which made him stable. Then he was prescribed with Tab. Lorazepam $(2 \mathrm{mg})$ twice daily; Tab. Tramadol $(100 \mathrm{mg})$ twice daily; Tab. Zolpidem $10 \mathrm{mg}$ and Tab. Mirtazapine $15 \mathrm{mg}$ at night. Other supportive medications like multivitamins were subsequently added. Psychosocial treatment included motivation enhancement counselling and 8 sessions of cognitive and behavioral therapy. He was discharged on $35^{\text {th }}$ day with satisfactory improvement (MSE shows no psychopathology; weight increased to $65 \mathrm{~kg}$ ). He is being regularly followed up and maintaining abstinence till date since his discharge from the hospital.

\section{DISCUSSION AND CONCLUSION}

WY abuse is increasing day by day particularly among the youths of Manipur. Manipur being a border state to Myanmar is most vulnerable. Precursors like pseudoephedrine and ephedrine are smuggled to Myanmar in large quantities in black market and in turn, huge amount of WY tablets are smuggled to Manipur. Undoubtedly, drug dependence is a dangerous situation. Law enforcing agencies also need to be proactive in dealing with drug related events. A more intensive research, action program, and social movements are needed to fight the menace of illegal drug trafficking, drug abuse and addiction. It is also needed to strengthen family and social values and religious ethics in order to maintain a stable and drug free society.

\section{REFERENCES}

[1]. RN Islam, NE Tabassum, AKM Shfiuzzaman , BU Umar , M Khanam .Methamphetamine (YABA) Abuse: A Case Study in Young Male. Faridpur Med. Coll. J. 2012;7(2):102-104

[2]. LG Shaun, K Fergus and B George B. Review article: Amphetamines and related drugs of abuse. Emergency Medicine Australasia (2008) 20, 391-402

[3]. W Charles, Meredith, C Jaffe, K Ang-Lee, J Andrew . Saxon. Implications of Chronic Methamphetamine Use:A Literature Review

[4]. Churchill A, Topp L. Methamphetamine forms. Drug Trends Bulletin. http://ndarc.med.unsw.edu.au/ndarc.nsf/website/IDRS.bulletins.[Accessed 19July 2003]

[5]. United Nations Office on Drugs and Crime. 2004 World drug report, vol 2:Statistics. Vienna; 2004.

[6]. Caulkins J. Methamphetamine epidemics: an empirical overview. Law Enforcement Executive Forum 2003; 3:17-42.

[7]. Jenner L, McKetin R. Prevalence and patterns of psychostimulant use. In: Baker A, Lee N, Jenner L, editors. Models of intervention and care for psychostimulant users. 2nd ed. National Drug Strategy Monograph Series No. 51. Canberra: Australian Government Department of Health and Ageing; 2004.

[8]. Degenhardt L, Topp L. 'Crystal meth' use among polydrug users in Sydney's dance party subculture: characteristics, use patterns and associated harm. Int J Drug Policy 2003; 14:17-24. 
[9]. Jane Carlisle Maxwell. Emerging research on methamphetamine. Curr Opin Psychiatry 18:235-242 \#2005 Lippincott Williams \& Wilkins. The University of Texas at Austin, Austin, Texas, USA

[10]. Wilkins C, Sweetsur P, Casswell S. Recent population trends in amphetamine use in New Zealand: comparisons of finding s from national household drug surveying in 1998, 2001, and 2003. Med. J. N. Z. 2006;119: 1-10.

[11]. Karch SB. Synthetic stimulants. In: Karch SB ed. The Pathology of Drug Abuse. Boca Raton: CRC Press, 1993; $165-234$.

[12]. Jerrad DA. Designer drugs - a current perspective. J. Emerg. Med. 1990; 8: 733-41. Review article: Amphetamines and related drugs of abuse Shaun L Greene, Fergus Kerr and George Braitberg Department of Emergency Medicine, Austin Health and Victorian Poisons Information Service,Melbourne, Victoria, Australia Emergency Medicine Australasia (2008) 20, 391-402.

[13]. Arnold, L.E., Huestis, R.D., Smeltzer, D.J., Scheib, J., Wemmer, D., \& Coiner, G. (1976). Levoamphetamine vs. dextroamphetamine in minimal brain dysfunction. Archives of General Psychiatry, 33, 292-301.

[14]. Barkley, R.A., DuPaul, G.J, \& Costello, A. (1993). Stimulants. In J.S. Werry \& M.G. Aman (Eds.), Practitioner's guide to psychoactive drugs for children and adolescents (pp. 205-237). New York: Plenum.

[15]. Katagi, M., Tatsuno, M., Miki, A., Nishikawa, M. and Tsuchihashi, H. (2000) Discrimination of dimethylamphetamine and methamphetamine use: simultaneous determination of dimethylamphetamine $\mathrm{N}$-oxide and other metabolites in urine by highperformance liquid chromatographyelectrospray ionization mass spectrometry.J. Anal. Toxicol., 24, 354-358.

[16]. Kraemer, T. and Maurer, H. H. (1998) Determination of amphetamine, methamphetamine and amphetamine-derived designer drugs or medicaments in blood and urine. J. Chromatogr.B, 713, 163-187.

[17]. Bell, S. E., Burns, D. T., Dennis, A. C. and Speers, J. S. (2000) Rapid analysis of ecstasy and related phenethylamines in seized tablets by Raman spectroscopy. Analyst (London), 125, 541-544.

[18]. Simpson DD, Joe GW, Dansereau DF, Flynn PM. Addiction treatment outcomes, process and change. Addiction. 2010; 10: 1360-69.

[19]. Shamim SB. A study on drug abuser in mohakhali slum. Journal of BIDS. 2005; 13: 13-18.

[20]. Tagaya H. Methaphetamine: Parmacology, indication and potenstial of abuses. Acta Med Port. 2010;68 (8) 1550-50.

[21]. Brecht ML, Urada DJ. Treatment out comes for methamphetamine users: California proposition 36 and comparison clients. Psychoactive drugs. 2011;7:68-76.

[22]. Rusyniak DE. Neurologic manifestation of chronic methamphetamine abuse. Neurol Clin. 2011; 29(3):641-55.

[23]. Brackins T, Brahm NC, Kissacl JC. Treatments for methamphetamine abuse: a literature reviews for the clinician. J Pharm Pract. 2011; 24(6): 541-50.

[24]. Zorick T, Neston L, Miotto K, Sugar C. Rawson R. Withdrawl symptoms in abstinent methamphetamine dependent subject. Addiction. 2010; 105 (10): 1809-19.

[25]. Reddy KSN. Drug dependence and Abuse. The essentials of Forensic Medicine and Toxicology. 26th edition. Hyderabad. 2007:531-37.

[26]. Fujita W, Takahashi M, Tokuyama S. The mechanism of the development of drug dependence. Prog Neuro biol. 2010; 64(8):1445-50. 